\section{Endoscopic ultrasound-guided radiofrequency ablation of a pancreatic neuroendocrine tumor}

Radiofrequency ablation (RFA), a method of achieving tumor necrosis by cell protein denaturation that is induced by heating tissues to above $45^{\circ} \mathrm{C}$, is applied in the treatment of several malignancies. Energy is provided by an RFA current generator, which is connected to an active electrode needle that is placed into the tumor under image guidance. The lesions created have variable diameters, depending on the intensity of the current used, the active tip length, and the treatment duration [1]. Recently a novel RFA needle (EUSRA RF Electrode; STARmed, Koyang, Korea) has been developed for use under endoscopic ultrasound (EUS) guidance [2]. It is an $18 \mathrm{G}$ water-cooled needle, with a long active tip of $5-30 \mathrm{~mm}(\bullet$ Fig. 1$)$, which is connected to a radiofrequency generator (VIVA RF generator; STARmed).

A 76-year-old man was referred for treatment of a pancreatic nodule. His laboratory results were within the normal ranges. An abdominal computed tomography (CT) scan showed a hypervascular 20-mm nodule in the pancreatic tail. EUSguided fine needle aspiration (FNA) revealed a pancreatic neuroendocrine tumor (pNET) with a Ki67 proliferative index of $>5 \%$, consistent with a G2 grading (๑ Fig. 2).

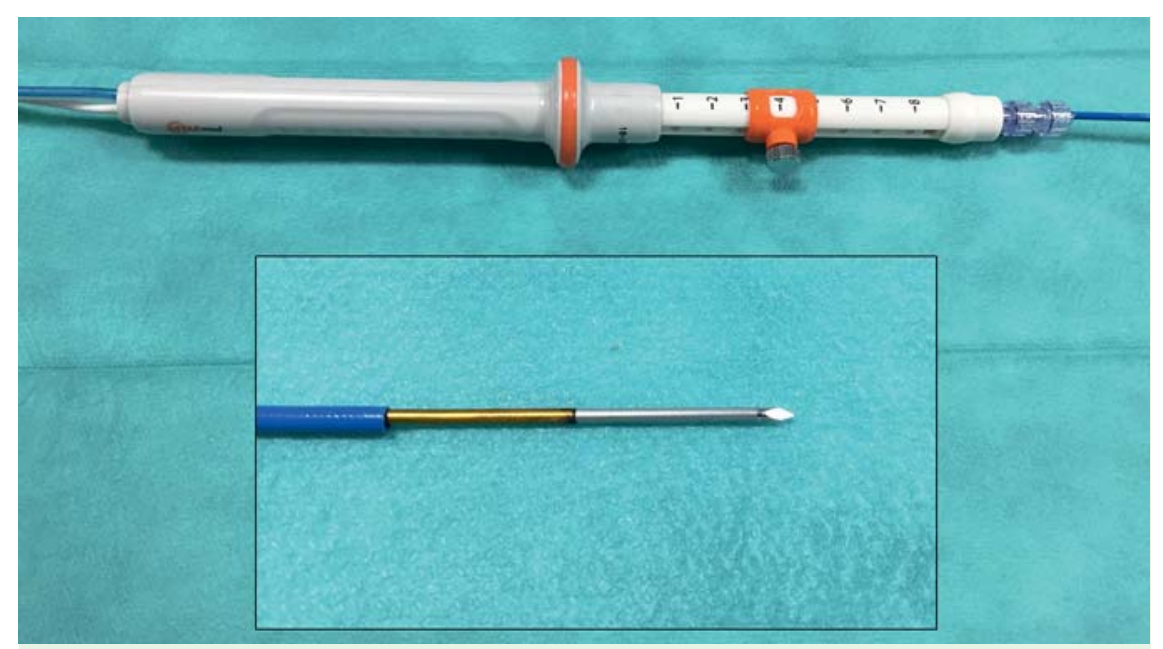

Fig. 1 The novel EUSRA radiofrequency ablation (RFA) needle, with a 10-mm active tip. The handle is connected to the water cooling device and to the VIVA RF generator.
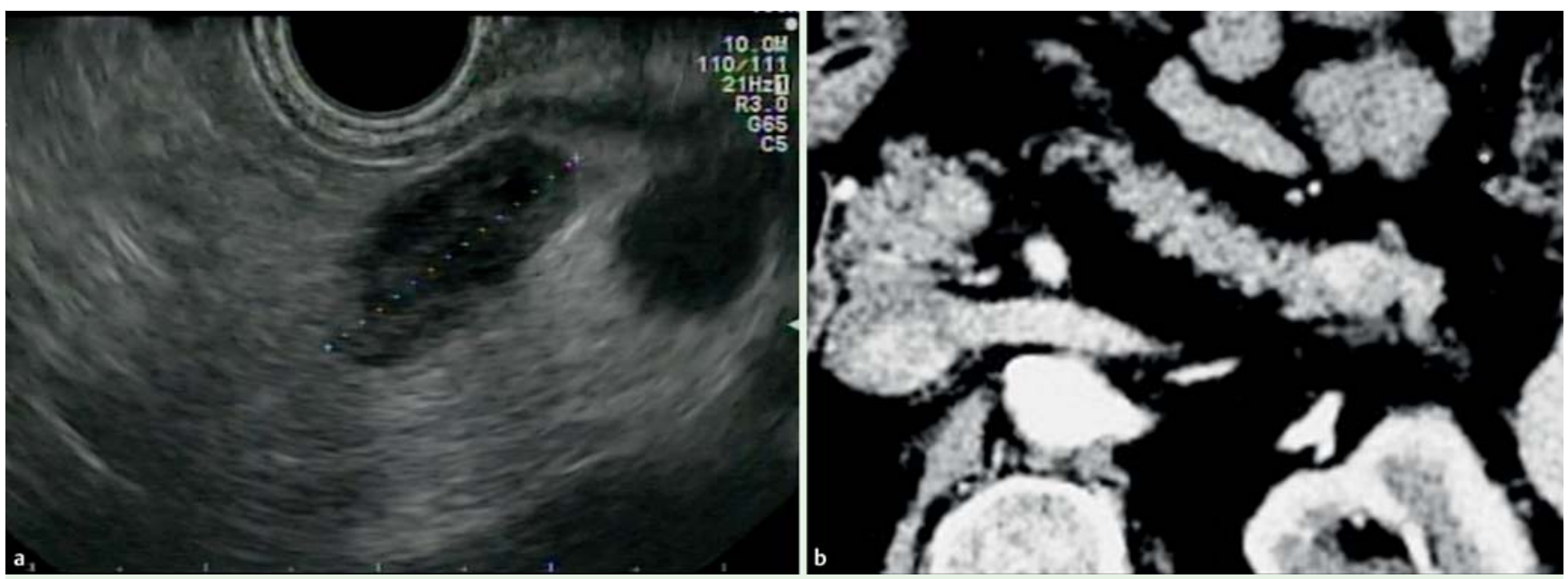

Fig. 2 Images of the nodule in the pancreatic tail on: a endoscopic ultrasound (EUS); b computed tomography (CT) scanning. 

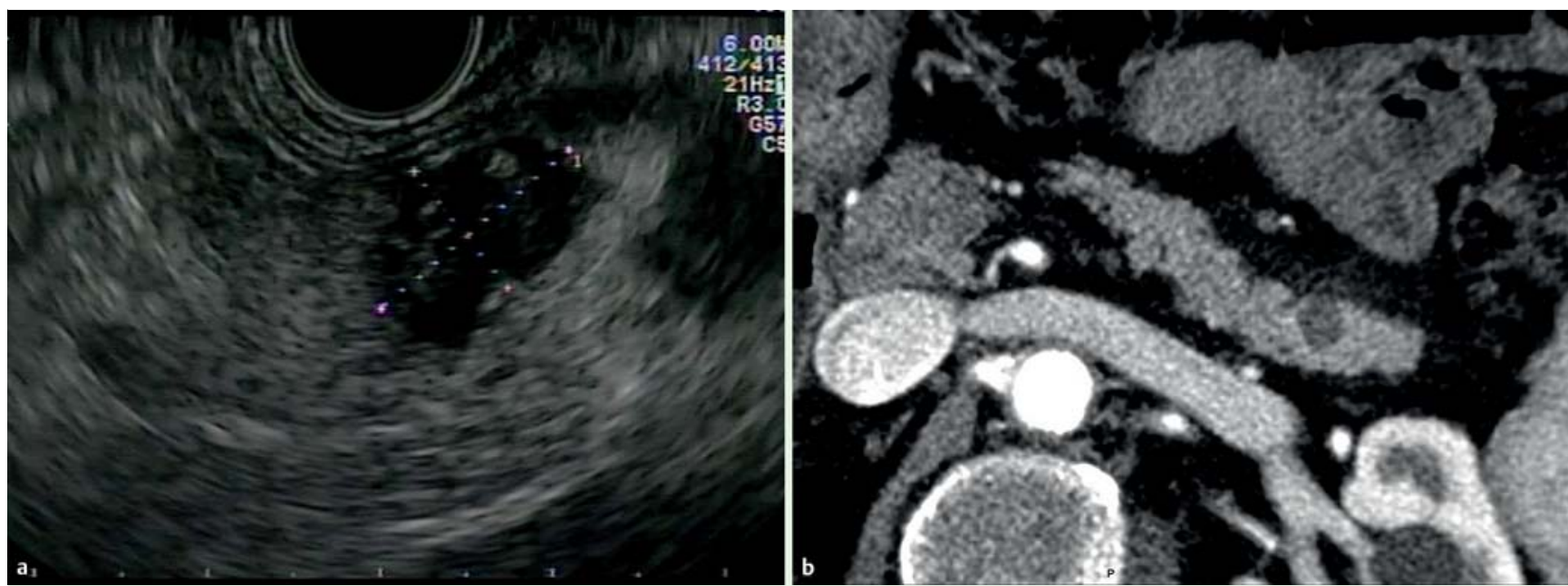

Fig. 3 Images taken 1 month after the endoscopic ultrasound (EUS)-guided radiofrequency ablation (RFA) showing: a on endoscopic ultrasound (EUS), a hypo/anechoic nodule; $\mathbf{b}$ on a computed tomography (CT) scan, a smaller round area without enhancement at the site of the previously ablated neuroendocrine tumor, consistent with necrotic tissue.

effective. This report adds to the increasing evidence of pNETs being successfully treated by ablative therapies, which may represent a potential alternative to surgery in selected cases [4-5].

\section{Endoscopy_UCTN_Code_TTT_1AS_2AD}

\section{Competing interests: None}

\section{Elia Armellini, Stefano F. Crinò, Marco Ballarè, Pietro Occhipinti}

Azienda Ospedaliero Universitaria “Maggiore della Carità”, Novara, Italy

\section{References}

1 Goldberg SN. Radiofrequency tumor ablation: principles and techniques. Eur J Ultrasound 2001; 13: 129-147

2 Kim HJ, Seo DW, Hassanuddin A et al. EUSguided radiofrequency ablation of the porcine pancreas. Gastrointest Endosc 2012; 76: $1039-1043$

3 Partelli S, Maurizi A, Tamburrino D et al. GEP-NETS update: a review on surgery of gastro-entero-pancreatic neuroendocrine tumors. Eur J Endocrinol 2014; 171: R153 R162

4 Yoon WJ, Brugge WR. Endoscopic ultrasonography-guided tumor ablation. Gastrointest Endosc Clin N Am 2012; 22: 359-369

5 Armellini E, Crinò SF, Ballarè M et al. Endoscopic ultrasound-guided ethanol ablation of pancreatic neuroendocrine tumours: a case study and literature review. World J Gastrointest Endosc 2015. In Press
Bibliography

DOI http://dx.doi.org/

10.1055/s-0034-1393677

Endoscopy 2015; 47: E600-E601

(c) Georg Thieme Verlag KG

Stuttgart · New York

ISSN 0013-726X

\section{Corresponding author}

\section{Elia Armellini, MD}

Department of Gastroenterology

Azienda Ospedaliero Universitaria

"Maggiore della Carità"

Corso Mazzini 18

28100 - Novara

Italy

Fax: +39-321-3733345

elia_armellini@hotmail.com 